\title{
Experimental Testing of the Applicability of Betatrons in Construction Radiography
}

\author{
O. Anton* \& V. Heřmánková \\ Brno University of Technology, Faculty of Civil Engineering, Brno, Czech Republic \\ *Corresponding author: anton.o@fce.vutbr.cz
}

\begin{abstract}
This paper focuses on testing the possibility of using portable betatrons in the radiography of reinforced concrete structures of greater thicknesses. The experiments were carried out in cooperation with the Research Institute of Introscopy in Tomsk (Russia).
\end{abstract}

KEY WORDS: Radiography, reinforced concrete, betatron.

\section{INTRODUCTION}

The properties of reinforced concrete structures with thicknesses of up to $0.6 \mathrm{~m}$ are tested by various non-destructive and destructive testing methods. However, for greater thicknesses of reinforced concrete structures, such as concrete bridge piers, massive foundations for rotating machines, and also massive shielding structures of linear accelerators and particularly of nuclear power plants, the standard methods often fail.

This was the reason for proposing a radiographic control method, which was then successfully tested, using a portable radiation source with the highest energy of breaking radiation so far - betatron MIB-7.5 MeV, which enables one to irradiate reinforced concrete structures and determine their macrostructure up to a thickness of $1 \mathrm{~m}$. Experimental irradiation of concrete samples with embedded reinforcement was carried out at the Research Institute of Introscopy in Tomsk (Russia).

\section{APPLICATION AREA OF BETATRONS}

Ionizing radiation sources with the energy of particles from 1 to $30 \mathrm{MeV}$ are applied in various areas of human activity. These are mostly the non-destructive testing (NDT) of materials and products, the evaluation of the inner contents of various objects without damaging them (control), and applications in health care.

Radioactive isotopes and various types of accelerators, such as betatrons, microtrons and linear accelerators, are now used in the above mentioned fields as the sources of ionizing radiation.

A betatron is a cyclic induction electron accelerator, where the energy of particles increases due to the eddy-current electric field, i.e. by changing the magnetic flux through the particle orbit. A betatron is the simplest accelerator, but it is inferior when compared 
to other types of contemporary accelerators. These properties determine the advantages and disadvantages of betatrons.

The first working betatron was assembled by D. Kerst in the USA in 1940. The first betatron in Russia was put into operation at the Tomsk Polytechnic University (TPU) towards the end of 1946.

The Research Institute of Introscopy (RII) was founded in 1968, at first as a designing department of the Tomsk Polytechnic University. Later on it gained total independence and now it has the status of a federal state research institution subordinate to the Ministry of Education and Science. On the grounds of the policy of reduction, the RII was again transferred under the jurisdiction of the Tomsk Polytechnic University on the basis of Russian Government regulation.

In the 1950s and 1960s, a number of countries produced betatrons with energies from 15 to $45 \mathrm{MeV}$ for use in non-destructive testing and health care. These were the socalled primary units, which were rather big and heavy. Later on, due to the quick development of microwave technology, these betatrons were replaced with linear accelerators able to provide 10 to 100 times higher dose rates.

Today, only the so-called "small-size betatrons" are required, the size and weight of which enables their transport to the objects tested. In the 1960s, the TPU started production of these small-size betatrons for energies from 3 to $6 \mathrm{MeV}$ for use in non-destructive testing under non-stationary conditions. Since the 1980s, the production of small-size betatrons has been one of the major tasks of the Research Institute of Introscopy. The Institute has become almost the only supplier of these devices for technological usage within Europe.

Small-size betatrons as the sources of radiation for non-destructive testing have a lot of advantages in comparison with other types of accelerators and radionuclide radiation sources. They have a slightly higher energy of radiation, small size of focus, the possibility of setting a maximum energy, a continuous range of breaking radiation. These properties enable the use of one unit for examining materials and products of a wide range of thicknesses. Apart from that, the issues of radiation safety are handled much more easily for small-size betatrons in comparison with the radionuclide sources.

However, as far as the acceleration principle used is concerned, standard betatrons do not allow for the acceleration of a higher number of electrons during one cycle, and this results in a lower dose rate when compared to other accelerators. That is why betatron designers primarily focus on increasing the dose rate. The latest models of small-size betatrons have had the dose rate increased 15 to 20 times when compared to the first samples; the size and weight have remained the same. Good radiation characteristics, simplicity and output reliability, as well as radiation safety in the OFF state ensure a sustainable demand for small-size betatrons, both in Russia and abroad. This demand consists in the price of a small-size betatron, which is several times lower than the price of a linear accelerator with the same energies.

Small-size betatrons produced nowadays in the Research Institute of Introscopy can be divided into the following groups:

1. Small-size betatrons for the non-destructive testing of materials and products. Most betatrons in this group can be used under non-stationary conditions.

2. Small-size betatrons of the control systems, including customs controls in applications for large containers, products and luggage.

3. Small-size betatrons with an extracted electron beam for medical purposes and radiation tests of electron products. 
The following technical solutions offering an effective application of betatrons and easy operation were implemented for the betatrons of the first group:

- setting up energy in a large range, which enables the checking of various thicknesses with a maximum speed

- using one's own dosimetric devices, consisting of a dosimeter placed behind the tested object and of a built-in dosimeter measuring the output dose. This allows one to skip experimental exposures completely and improve the quality of films;

- fully automatic control by microprocessor systems carrying out the setup and stabilization of all the parameters of the accelerator, switching off the source of radiation after achieving the preset dose on the basis of information in the built-in dosimeter, as well as on the basis of the time signal. Thus, the only thing the operator must do is to press the button triggering the radiation;

- small sizes and weights, which allows one to use most types of small-size betatrons under non-stationary conditions.

- setting the repeat frequency of radiation impulses to reduce consumption, which facilitates work under field conditions using low-energy sources.

Technical characteristics of betatrons used today in non-destructive testing are summarized in Table 1.

Table 1: Technical characteristics of contemporary betatrons.

\begin{tabular}{|c|c|c|c|c|c|c|}
\hline \multirow[b]{2}{*}{ Number } & \multirow[b]{2}{*}{ Characteristic } & \multicolumn{5}{|l|}{ Model } \\
\hline & & $\begin{array}{l}\text { MIB- } \\
3.5 \\
\text { „Axis“ }\end{array}$ & $\begin{array}{l}\text { Betatron } \\
\text { „TOMO“ (for } \\
\text { tomography) }\end{array}$ & $\begin{array}{l}\text { MIB-6 } \\
\text { (PXB- } \\
6)\end{array}$ & $\begin{array}{l}\text { MIB- } \\
7.5 \\
(\mathrm{MXB}- \\
7.5)\end{array}$ & $\begin{array}{l}\text { MIB-10 } \\
\text { (KRAB) }\end{array}$ \\
\hline 1 & $\begin{array}{l}\text { Energy setup range, } \\
\mathrm{MeV}\end{array}$ & 2 to 3.5 & 3 to 5 & 2 to 6 & 2 to 7.5 & 3 to 10 \\
\hline 2 & $\begin{array}{l}\text { Dose rate at } 1 \mathrm{~m} \text { from } \\
\text { the target point in the } \\
\text { peak, } \mathrm{R} / \mathrm{min}\end{array}$ & 2.7 & 4 & 3 & 5 & 20 \\
\hline 3 & $\begin{array}{l}\text { Sizes of foci } \\
\mathrm{mm} \times \mathrm{mm}\end{array}$ & $0,3 \times 3$ & $0,3 \times 3$ & $0.3 \times 3$ & $0.3 \times 3$ & $0.3 \times 3$ \\
\hline 4 & Maximum PRR, C-1 & 400 & 400 & 200 & 200 & 150 \\
\hline 5 & $\begin{array}{l}\text { Maximum thickness } \\
\text { of steel for } \\
\text { attenuation, mm }\end{array}$ & 150 & 150 & 200 & 250 & 350 \\
\hline \multirow[t]{3}{*}{6} & $\begin{array}{l}\text { Unit weight: kg } \\
\text { Source of radiation }\end{array}$ & 55 & $\begin{array}{l}500 \\
\text { (shielding) }\end{array}$ & 97 & 105 & 275 \\
\hline & Feeding & 56 & 35 & 51 & 63 & 80 \\
\hline & Control Panel & 1.0 & 1.0 & 1.0 & 1.0 & 1.7 \\
\hline 7 & $\begin{array}{l}\text { Energy consumption } \\
\text { at the max. } \\
\text { frequency, } \mathrm{kW}\end{array}$ & 2.2 & 2.5 & 2.0 & 2.5 & 3.6 \\
\hline
\end{tabular}

Betatron MIB-7.5 is the most commonly used product today. 
At the moment, there is no information available that betatrons, including small-size betatrons, would be manufactured by any other organization than RII.

So far, however, the use of betatrons has, in fact, been limited to radiography in mechanical engineering, i.e. irradiation of massive metal elements. This is why we have established a partnership with the Research Institute of Introscopy, with the aim to test the actual possibilities of using their most perspective model of betatron MIB-7.5 for the irradiation of higher thicknesses of reinforced concrete.

\section{PRINCIPLE AND DESCRIPTION OF BETATRON}

A betatron is a cyclic induction electron accelerator producing high-energy radiation, the socalled breaking radiation, as a result of a conversion of kinetic energy of electrons during their collisions with the target. Electrons are accelerated by the eddy-current electric field, i.e. by changing the magnetic flux on the closed particle orbits. The alternating magnetic field is induced in the electromagnet of betatron by means of magnetic coils and profiled pole pieces, around which there is a toroidal vacuum accelerator chamber.

A betatron consists of three main units: the source of radiation, the power unit, the control panel and two additional units - the stand-alone dosimeter and the light alarm unit that are used as needed. The scheme of betatron MIB-7.5 is shown in Fig. 1.

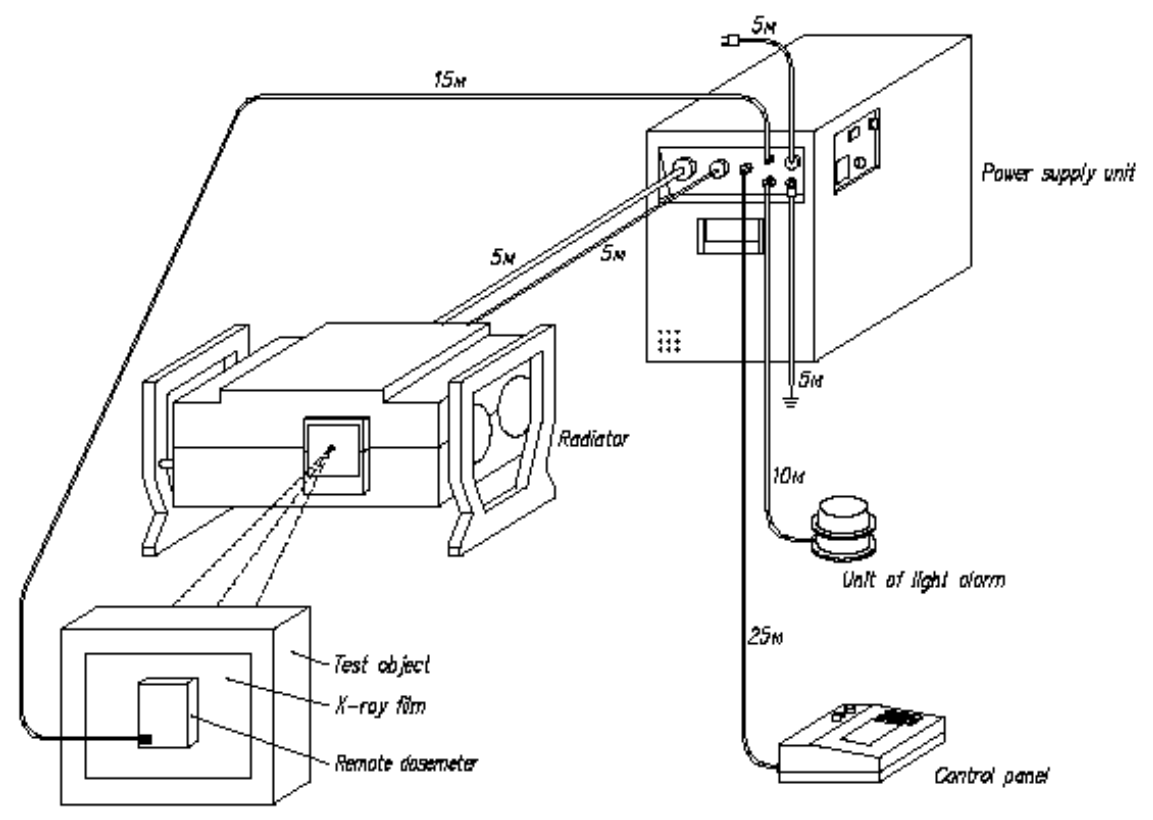

Figure1: Betatron MIB-7.5.

\section{BETATRON MIB-7.5 BASIC DATA FOR THE RADIOGRAPHY OF CONCRETE}

Betatron MIB-7.5 is recommended for the irradiation of building constructions made of concrete or other materials with a thickness from 200 to $900 \mathrm{~mm}$. The limiting thickness for concrete is $1200 \mathrm{~mm}$, and it is limited by the exposure time. The maximum exposure time is determined by the time when betatron can be in operation in one cycle. Here, therefore, we can see a limitation in comparison with the radioactive sources.

The breaking radiation of betatron has a continuous energy spectrum and theoretically it contains quanta of photons in the extent from the maximum value (equal to the kinetic 
energy of accelerated electrons) to zero. In the case of shielding it is recommended to use the term "effective energy". According to the documentation its value equals a half of the maximum value.

Half-thickness (an important shielding parameter) for energies 7.5 and $5 \mathrm{MeV}$ for concrete is $110 \mathrm{~mm}$ and $91 \mathrm{~mm}$.

The main radiation parameters monitored - sensitivity and quality of the film - are defined by the sensitivity and contrast of the radiographic film emulsion and by the type of intensifying foils. Intensification in metal foils is based on the subsequent influence of electrons on the radiographic film. The foils are made of heavy metals (lead, tungsten, tin, tantalum, etc.). The intensifying effect of the foils depends on the thickness of the front and rear foils, the energy of the radiation, and on some additional factors. Sensitivity depends on a number of factors: energy, focus, the thickness and the shape of the product, film type, intensifying foil, focal distance and the experience of the operators. Quality of the film is monitored by means of wire gauges.

The exposure time of betatron can be set up on the basis of an exposure diagram (Fig. 2) or a built-in dosimeter.

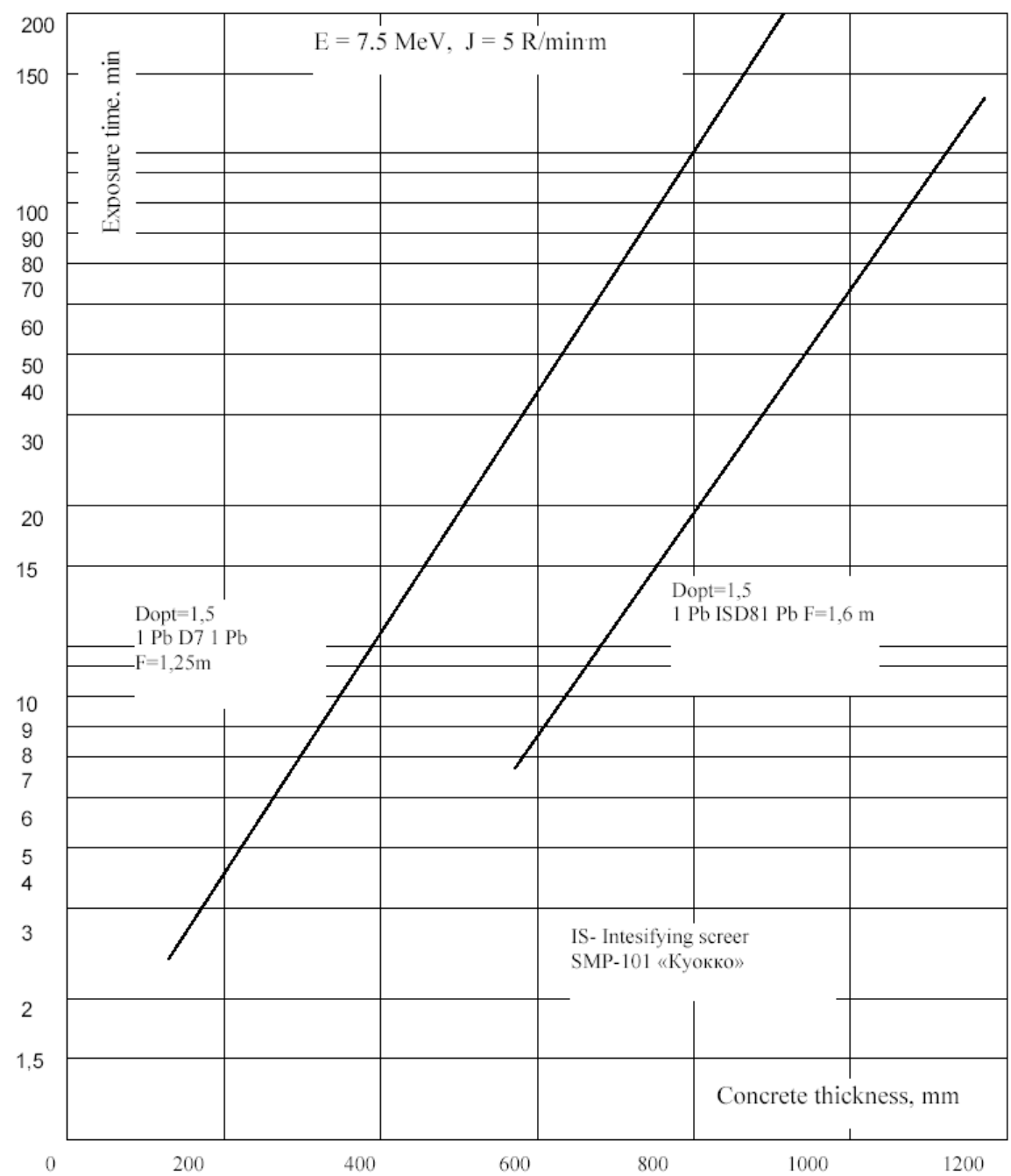

Figure2: Diagram of exposure times for concrete. 


\section{TESTING THE USE OF BETATRON MIB-7.5 IN THE RADIOGRAPHY OF REINFORCED CONCRETE - EXPERIMENT}

The aim of the experimental work was a preliminary determination of the maximum thickness of irradiated concrete and of the sensitivity of imaging using betatron with the energy of 7.5 MeV as the source of radiation.

In the laboratory of the Research Institute of Introscopy in Tomsk, an experimental path was assembled according to the instructions, similar to the one in the laboratory of the Radiation Defectoscopy Centre in Brno.

It consisted of concrete slabs with dimensions of 500 x 500 x $100 \mathrm{~mm}$.

One slab contained rods of steel reinforcement of class 10216 with diameters of 36, 25, 18 and $10 \mathrm{~mm}$ placed horizontally. Unfortunately, irradiation of other types of reinforcement was not agreed with the Centre. The slab with reinforcement was placed second in order; the depth of reinforcement placement was therefore approximately $150 \mathrm{~mm}$.

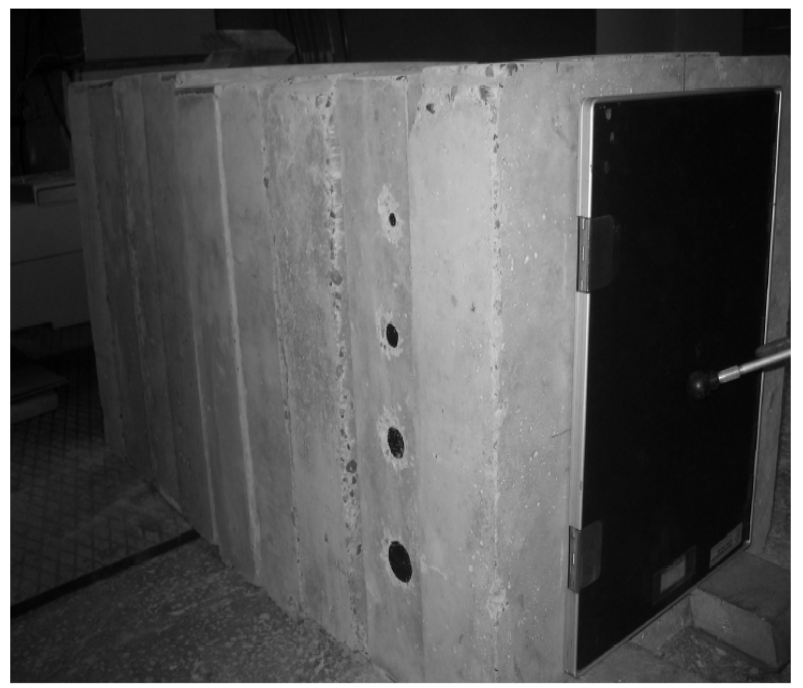

Figure3: Experimental path in Tomsk, ends of steel reinforcement apparent in the 2 nd slab.

What is interesting in this case is the use of wire gauges, which was not a problem thanks to a greater focal distance. The wire gauge was made as the so-called irradiation standard, in accordance with the local practice.

A detailed picture of this standard is shown in Fig. 5. The diameters of individual wires were: 3, 4, 5, 6, 7, 8, 9 and $10 \mathrm{~mm}$, and their length was $100 \mathrm{~mm}$. The gauge was fixed to a fiberglass plate with a thickness of $2 \mathrm{~mm}$. The distance between the wires was $7 \mathrm{~mm}$.

A solid cassette with a radiographic film $30 \times 40 \mathrm{~cm}$ was placed immediately against the rear edge of the last slab. The film was placed between two steel foils with a thickness of $1 \mathrm{~mm}$ (using steel foils for betatron is adequate to lead foils when irradiating with Co-60). All the images were exposed on standard Agfa D7 films.

The spherical chamber of clinical dosimeter 27012 (made in Germany) was placed behind the cassette and into its centre. The exposure was carried out with a view to a possible dose at this dosimeter. At the same time, the exposure time and the dose achieved by the betatron internal dosimeter were registered. It is worth mentioning that the internal dosimeter of betatron is calibrated by clinical dosimeter 27012, the spherical chamber of which is situated on the beam axis at a distance of $1 \mathrm{~m}$ from the target. The focal distance between the target of betatron and the cassette was $1.5 \mathrm{~m}$ for all images. 
On the basis of the previous experiments, the maximum density of blackening was chosen to be $\mathrm{D}=3.0$. All films were developed manually. The blackening was measured in two sections, in the centre of the image containing no horizontal or vertical rod, and in the lower part of the image along the line close to the edge of the horizontal rod with the highest diameter. Five points were measured and these data were used for determining the average density of blackening.

Table 2: Characteristic parameters of radiograms taken.

\begin{tabular}{|l|l|l|l|l|}
\hline Image number & 1 & 2 & 3 & 4 \\
\hline Thickness of concrete [mm] & 600 & 700 & 800 & 900 \\
\hline Dose behind the film [mGy] & 19 & 18 & 18 & 18 \\
\hline Exposure time [min.] & 24 & 52 & 77 & 124 \\
\hline Dose of internal dosimeter [Gy] & 1.60 & 3.20 & 4.72 & 7.60 \\
\hline Optical density in the image centre & 2.64 & 3.00 & 2.58 & 2.37 \\
\hline Optical density in the image margin & 1.90 & 1.96 & 2.03 & 1.79 \\
\hline Min. discernible of steel wire [mm] & 3 & 3 & 3 & 4 \\
\hline
\end{tabular}

The total exposure time of images 3 and 4 was completed only after a 15 min break in the exposure (after 45 min run) because of a complete cooling of the betatron.

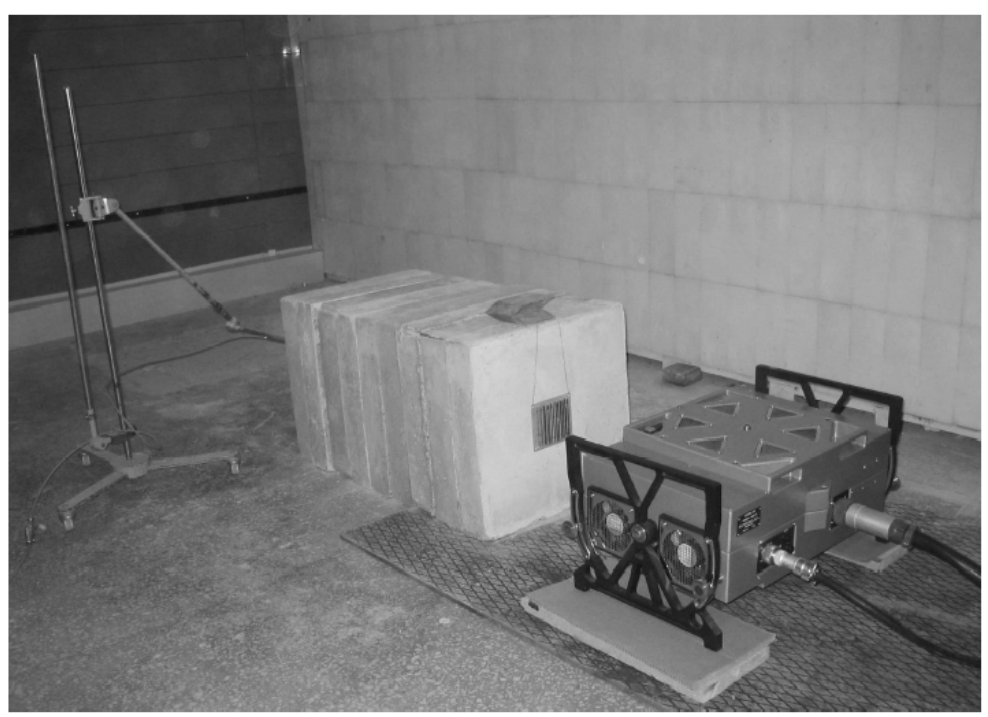

Figure 4: Scheme of the experiment in Tomsk - betatron MIB-7.5 and the experimental path.

During the evaluation of radiograms it was ascertained that all reinforcement rods in all radiograms are unambiguously visible. The quality of radiograms was almost identical regardless of thickness. Also regardless of thickness we can therefore presume the possibility to identify the reinforcement type. In all images it can be estimated that it would be possible to identify the type of reinforcement with diameters of 25 and $36 \mathrm{~mm}$, but not so in the case 
of lower diameters. Unfortunately, a comparison with an image of rebar reinforcement was not possible (due to limiting the original scope of tests).

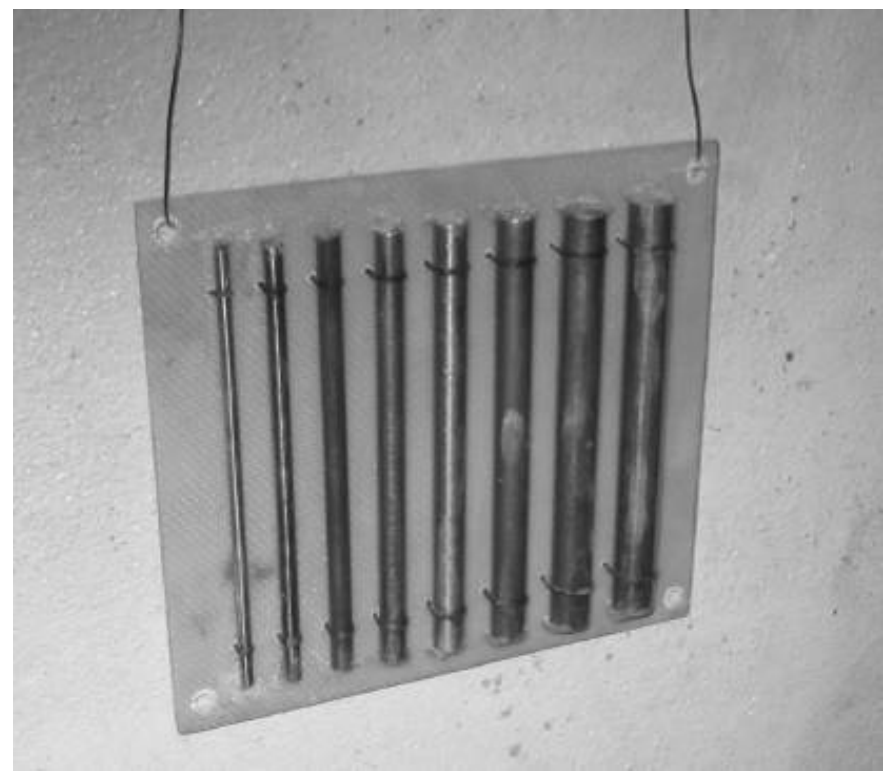

Figure 5: Wire gauge made up of wires with diameters of $3,4,5,6,7,8,9$ and $10 \mathrm{~mm}$, in accordance with local standards.

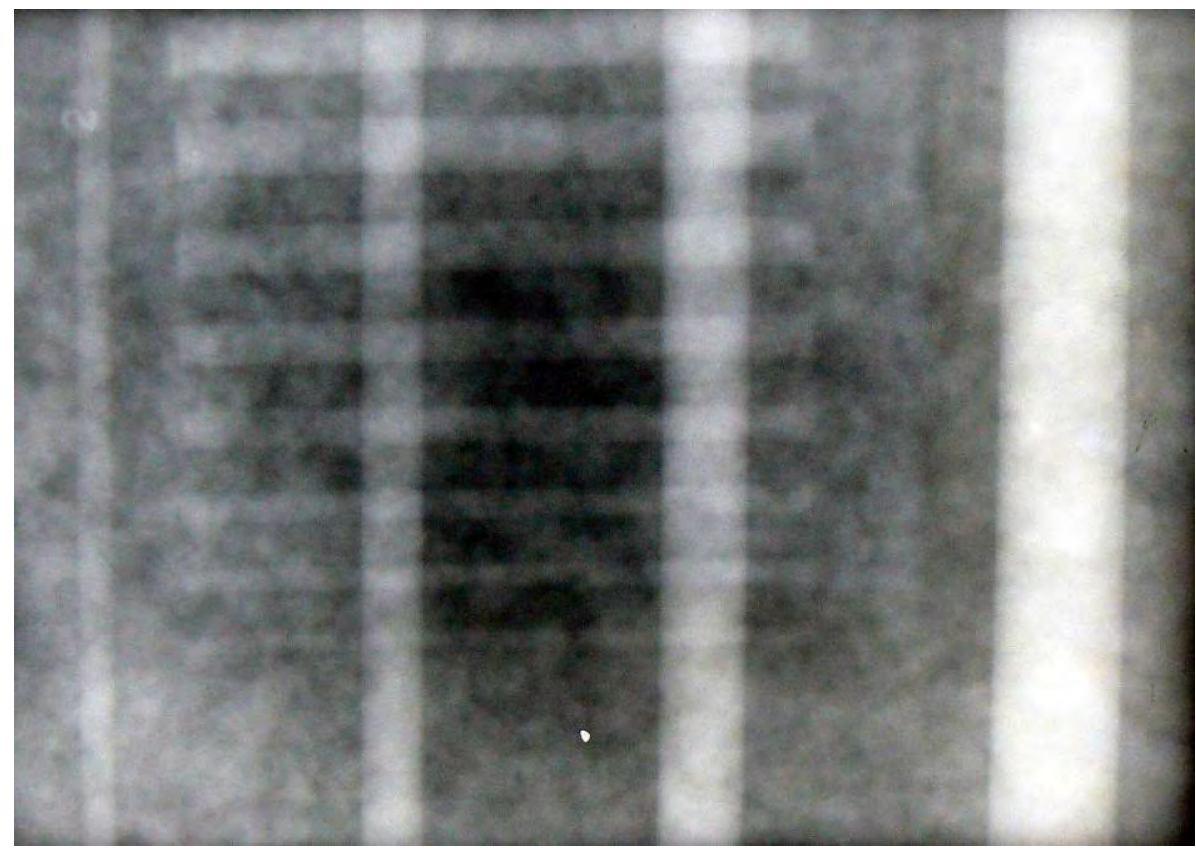

Figure 6: Radiogram at a concrete thickness of $600 \mathrm{~mm}$.

\section{RESULTS OF THE EXPERIMENT USING BETATRON MIB-7.5}

The experiments carried out do not implement fully all the possibilities of concrete structure testing using betatron MIB-7.5 (it would be possible to increase the irradiated thickness 
of concrete even more). In spite of this, we can summarize the conclusions of the experiment in the following points:

- Steel reinforcement rods in the concrete are clearly visible. Even in the worst case, when the reinforcement is close to the edge of the concrete structure and is directed towards the radiation source, the sensitivity was not worse than $0.5 \%$.

- The analysis of radiograms allows us to draw some conclusions about the quality of concrete. Insufficient homogeneity of concrete is clearly visible in all the images. The reason for this is that the concrete blocks used were made manually and the content of concrete fractions was not checked.

- The non-homogeneity of blackening is also well visible, which is caused by the nonhomogeneity of the radiation beam of betatron. With a focal distance of $1.5 \mathrm{~m}$ and in an image with dimensions of $300 \times 400 \mathrm{~mm}$, the non-homogeneity of blackening from the centre to the edge could be 0.6 to 0.7 blackening units on average. This does not visually influence the detectability of the defect too much. In spite of that, for achieving good density imaging in the centre, approximately 3 units of optical density should be optimal.

- Also worth noting is the apparent haze near the rods at a concrete thickness of $800 \mathrm{~mm}$, and especially at a thickness of $900 \mathrm{~mm}$. This is related to a great optical magnification of about 2.5 times at a thickness of $900 \mathrm{~mm}$. This is the reason why the focal distance at a concrete thickness of $800-900 \mathrm{~mm}$ should be at least $2 \mathrm{~m}$.

- When we use the D7 film with lead foils, the exposure time is too long. Starting with the thickness of $700 \mathrm{~mm}$, it is impossible to get an image within the time corresponding to one betatron cycle. This is the reason why it is necessary to study the effective use of betatron MIB-7.5 in testing great thicknesses of concrete which reduce the exposure times.

According to the description of betatron, if the D8 film is used with a SMP-101 "Kyokko" intensifying foil, it is possible to reduce the exposure time approximately 7 to 8 times, but at the price of lowering the quality of radiograms.

Another possible way of reducing the exposure time is the new methodology of radiographic control: memory foils, scanners for the reading and digitalization of their images and further digital processing for improving the quality of images.

The Research Institute of Introscopy focuses on this issue at the moment. It has recently bought memory foils and HD-CR 35 NDT scanners made by the German company "DÜRR NDT" and software packages Video Ren made by the company "Unitest-Roentgen (St. Petersburg)" for processing images. They are being studied at the moment, but their description indicates neither instructions for use, nor the characteristics of sheets: sensitivity to doses, resolution, etc.

The experiments are in progress at the moment.

As a conclusion it is possible to state that the use of betatron MIB-7.5 in construction radiography is basically possible, and even for the irradiation of higher thicknesses of concrete than Co-60 radiography normally allows. The necessary exposure times are incomparably shorter, but on the other hand, it is necessary to switch off and cool the device between the maximum exposure times, which prolongs and complicates the whole process. 
Moreover, due to its size and weight, the device is designated for only exceptional use in the field, in some extraordinary and well-founded cases. This, apart from its high purchase cost, is also the reason why its use has not yet spread widely. At the moment, memory foils are tested, the use of which could shorten the exposure times to values not approaching the boundary exposure times, which could lead to a wider proliferation of the device.

\section{REFERENCES}

Anton, O.; Heřmánková, V. Možnost užití betatronů při radiografii masivních konstrukcí. In Zkoušení a jakost ve stavebnictví 2009. Brno, VUT v Brně. 2009. p. 49 - 59. ISBN 97880-214-3951-1.

Luňáček, M.; Anton, O.; Vymazal, T. Př́prava masivních bloků pro projekt „Metodika zkoušení masivních železobetonových konstrukcí “. In Juniorstav 2007. Brno, VUT v Brně, Fakulta stavební. 2007. p. 166 - 173. ISBN 978-80-214-3337-3. 